\title{
Perivascular Lymphocytic Infiltrate
}

National Cancer Institute

\section{Source}

National Cancer Institute. Perivascular Lymphocytic Infiltrate. NCI Thesaurus. Code C62777.

A morphologic finding indicating the presence of a non-neoplastic or neoplastic lymphocytic infiltrate surrounding vessels. 